\title{
Strange linearities in human pregnancy. The immediate immense consequences for personal women's reproductive lives
}

\author{
Pierre-Yves Robillard ${ }^{1,2}$, Malik Boukerrou ${ }^{2,3}$ and Thomas C Hulsey ${ }^{4}$ \\ ${ }^{1}$ Neonatology Department, Centre Hospitalier Universitaire Sud Réunion, BP 350, 97448 Saint-Pierre Cedex, Réunion, France \\ ${ }^{2}$ Center for Perinatal Studies in the Indian Ocean (CEPOI), Centre Hospitalier Universitaire Sud Réunion, BP 350, 97448 Saint-Pierre cedex, La reunion, France \\ ${ }^{3}$ Service of Gynecology and Obstetrics, Centre Hospitalier Universitaire Sud Réunion, BP 350, 97448 Saint-Pierre cedex, La reunion, France \\ ${ }^{4}$ Department of Epidemiology, School of Public Health, West Virginia University, Morgantown WV, USA
}

\begin{abstract}
Maternal ages categories (by 5 years of age, 15-19, 20-24, 25-29 etc.) as well as pre-pregnancy body mass index (BMI), also interestingly by categories of $5 \mathrm{~kg} / \mathrm{m}^{2}$ (15$19 \mathrm{~kg} / \mathrm{m}^{2}, 20-24$ etc..) have both linear associations with important maternal/fetal morbidities. For maternal ages: rate of cesarean sections, vaginal deliveries, active vaginal procedures (vacuum, forceps etc.), incidence of breech presentation at term, placenta praevia. For pre-pregnancy BMI, allowing to define optimal gestational weight gain (GWG) for the index pregnancy: : rate of cesarean sections, vaginal deliveries, rates of large or small for gestational ages newborns (LGA\&SGA), rate of macrosomic babies ( $\geq 4 \mathrm{~kg}$ ), and incidence of late-onset preeclampsia ( $\geq 34$ weeks gestation, 80 to $90 \%$ of preeclampsia cases in a population).

Conclusion: These linear associations (biological mathematical laws?) suggest underlying biological principles to investigate. It implies immediate practical consequences: First, prediction since the beginning of any pregnancy of important maternal/fetal morbidities. Second, by calculating optimal gestational weight gain, should permit to lower these important complications. Third, because of these linearities maternal ages as well as pre-pregnancy BMI divided by increments of 5 (or as continuous variable) should be in the future included in quite all logistical models in epidemiological perinatal studies.
\end{abstract}

\section{The problem of overweight/obesity in obstructed labour}

The "adventure" began in 2005. We were with my obstetrician friend Georges Barau in the room next to the amphitheatre after an emergency caesarean section, it was around 11 p.m. at night during a call. He told me "we obstetrician have been obsessed and taught on bone-pelvis dystocia. But, nowadays, with good nutrition and disappearance of massive rickets in temperate countries, this 'bone dystocia' is no more the problem. I think that nowadays the dystocia problem might be rather due to 'soft tissue dystocia' namely the pelvis fatness. Have a look to your data and see if there is an association between BMI and rate of c-sections". If there was something, we both thought to find that the association between BMI and rate of $\mathrm{c}$-section should be like a $U$ curve; high in very lean women, relatively low in normal shaped women and then high in obese ones [1]. Our surprise was to discover that indeed it was a linear curve from "meagers" to "normal", overweight, and all kinds of obesities (class I to III). Lean women delivered vaginally better than women $20-24 \mathrm{~kg} / \mathrm{m}^{2}$ [1].

The problem of adolescent ( $<18$ years of age) and teenage (<20) pregnancies. Another debate on obstructed labour

In Reunion island, we still had in the first decade of the 2000's (it is beginning to disappear nowadays with the important rise of the level of education in our youth the last ten years) an important problem of adolescent pregnancies (before 18 years of age): $4 \%$ of our deliveries (and $11 \%$ of our primiparas) were adolescent, very well socially accepted in Reunion island, and integrated in reunionese families [2]. We did several studies on the subject [3-5], plus or minus suggested by our health authorities who wanted to "fight the problem" and have reliable epidemiological data. We did at first our research within back mind the "Frazer seminal model" i.e. that adolescent pregnancies are a kind of catastrophy in terms of perinatal adverse outcomes [6]. We were surprised to find that, indeed adolescent mothers had twice risk of early pre-term (<33 weeks gestation) new-borns than their 20-29 year counterparts ( $4 \%$ vs $2 \% \#$ ), but for all the obstetrical side they did much better than older primiparas [3-5], constantly with a linear rise.

\#4\% of early preterms means also in mirror that $96 \%$ of babies had a good survival chance in absence of modern neonatology, which was the case during $99.9 \%$ of Homo sapiens existence.

Then, we went further, only focusing on primiparous deliveries (these deliveries are by far much longer and "laborious" then multiparous ones) and obstructed labours (cause of several million of maternal deaths since the beginning of our species).

In another report, we found five linear trends associated with maternal ages in primiparae from 12 years to $42+.1$ ) vaginal deliveries without any medical intervention, "natural birthing" [7] 2) and 3) rate of caesarean sections and rate of operative vaginal procedures (vacuum,

${ }^{\star}$ Correspondence to: Pierre-Yves Robillard, Neonatology Department, Centre Hospitalier Universitaire Sud Réunion, BP 350, 97448 Saint-Pierre Cedex, Réunion, France, Tel: (262) 2623591 49, Fax: (262) 2623592 93; E-mail: pierre-yves.robillard@chu-reunion.fr

Key words: pregnancy, epidemiology, pre-pregnancy body mass index, gestational weight gain, caesarean section, obesity, adolescent pregnancies, teenage pregnancies

Received: March 02, 2020; Accepted: March 16, 2020; Published: March 19, 2020 
forceps, spatulas,) these 2 last being in mirror with vaginal deliveries. 4) spontaneous breech presentation at term was also a linear curve; if you are 18 years old, the incidence is $1.8 \%$, if you are 35 the risk is $3.5 \%$ (the linear equation being $\mathrm{y}=0.1 \mathrm{x}$ ) [8]. 5) Further, and finally, we tested natural occurrence of spontaneous dangerous placenta praevia in primiparas (synonymous of maternal death by bleeding without caesarean section): it is very low (quite inexistent) in very young mothers and increases linearly with advancing maternal ages.

The resultant of these findings leads to a simple equation: $y=1.4 x$. [9]

( $\mathrm{y}$ being active medical interventions, $\mathrm{x}$ maternal age at birth)

$\mathrm{Y}=1.4 \mathrm{X}$ means that at 16 years old at your first birth, your risk of requiring active obstetrical medical intervention is $22 \%, 30$ years old (the current average age at first birth in Europe nowadays) $42 \%$, at 39 years: $55 \%$. We proposed that "These 5 consistent linear laws concerning human first births are difficult to understand without hypothesizing an underlying biological principle. Before the start of modern obstetrics, young women were condemned to begin their reproductive lives during puberty, because of absence of any type of contraception and a short expectancy of life." Indeed, during $99.8 \%$ of our species' existence (2 to 300,000 years) women have delivered with the only help of their female's friends, family, or matrons. Also, we concluded that "Primiparous women appear to be protected against maternal deaths at birth (severe dystocia by cephalopelvic disproportion, need for vaginal operative help, breech presentation and placenta praevia) at younger ages." [9]. These findings suggest then that women have been "shaped" by evolution to have their first babies at young ages, exactly like all other 4,500 mammal's species. It confirms that puberty is strictly synonymous of beginning of reproduction in all the mammalian kingdom.

It is therefore fundamental and of interest for women to know that it is probably better to have their first child before 25 years of age. Over, we become highly dependent of nowadays' modern obstetrics (namely the safety of c-section procedures, which were considered as dangerous until the 1960's).

\section{The problem of gestational weight gain}

Knowing the optimal gestational weight gain (GWG, from conception to birth) among the annual 135 million of human pregnancies is considered to be one of the "Holy Grails" to achieve for maternity health care providers and for women themselves. Extensive literature exists on the subject with, in background, the current international cornerstone which is the 2009-IOM recommendations [10] based on the WHO-BMI classification standardized in 2000 [11]: underweight women (before pregnancy) $<18.5 \mathrm{~kg} / \mathrm{m}^{2}$ should have a GWG between 12.5 and $18 \mathrm{~kg}$, normal weight, $18.5-24.9 \mathrm{~kg} / \mathrm{m}^{2}$, a GWG of $11.5-16 \mathrm{~kg}$, overweight, $25-29.9 \mathrm{~kg} / \mathrm{m}^{2}$, a GWG of 7-11.5 kg, and obese $>30 \mathrm{~kg} / \mathrm{m}^{2}$ a GWG of $5-9 \mathrm{~kg}$. Since then a lot of controversies aroused on these recommendations (Asian people claiming that their women are leaner than Caucasians, on the other side people having a lot of obese women in their populations). We already extensively discussed these controversies in another paper [12].

Based on the simple axiom: "what is the optimal gestational weight gain at term (optGWG) to achieve the natural rate of $10 \%$ of SGA (small for gestational age) as well as $10 \%$ of LGA (Large for gestational age) in newborns in my population", we have found in Reunion island (French overseas Department in the Indian Ocean, nearby Mauritius island) the mathematical linear equation:
$\operatorname{optGWG}(\mathrm{kg})=-1.2 \mathrm{ppBMI}\left(\mathrm{Kg} / \mathrm{m}^{2}\right)+42 \pm 2 \mathrm{~kg}[12]$.

optGWG being optimal gestational weight gain. ppBMI being prepregnancy BMI.

As a matter of fact, if we consider crude results on a reproductive population, only women with a normal BMI achieve an equilibrium in the SGA/LGA risk (both 10\%). Very thin mothers have a higher risk of small for gestational age (SGA) infants, and rarely give birth to a large for gestational age (LGA) infant. While morbidly obese women often give birth to LGA infants, and rarely to SGA. This equilibrium in the SGA/LGA risk (both 10\%) is materialized geometrically by a crossing point of both SGA/LGA curves. Associated with different maternal corpulences, we proposed to call this $10 \%$-crossing point the Maternal Fetal Corpulence symbiosis (MFCS) [12].

The reflection then was to test if the corpulence of 2 separate individuals (mother and foetus) had a mutually interactive dependency concerning their respective weight, by testing the MFCS by each BMI categories $5 \mathrm{~kg} / \mathrm{m}^{2}$ by $5 \mathrm{~kg} / \mathrm{m}^{2}$. We found that there is a regular shift from the right to the left beginning with lean women towards obese ones to achieve the famous MFCS point (lean women necessitate to have a weight gain around $20 \mathrm{~kg}-\mathrm{vs} 12.5-18$, IOM-, normal shaped ones around $14 \mathrm{~kg}$, overweight around $6 \mathrm{~kg}-\mathrm{vs} 7-11.5$, IOM- etc... AND severe obese beginning at $36 \mathrm{~kg} / \mathrm{m}^{2}$ should lose weight during pregnancy -vs plus 5 to $9 \mathrm{~kg}$, IOM- [12]. In fact, the result is the above described linear equation. It is of note that, since it is a mathematical linear equation it allows that EACH WOMAN may be considered as a SINGLE PLOT and that we may calculate for each woman at the beginning of pregnancy her individualized optimal gestational weight gain optGWG for that pregnancy. This is of paramount importance because we no more classify women in "guilty categories" (underweight/normal weight/overweight/obese class I/obese class II). Each woman has now her personal goal to possibly achieve.

We have put an online calculator consultable on smart phone at REPERE.RE (REseau PErinatal REunion), in three languages (French, Spanish and English) [13], adapted to the Reunionese women. We encourage any reader to validate these findings adapted to their own populations (it is easy to do if you know the specific SGA/LGA curves of your term -37-42 weeks gestation- newborns).

\section{Major practical consequences for each woman to achieve an optimal gestationalweight gain (optGWG)}

First, we have recently described that increased BMI has a linear association with late-onset preeclampsia (LOP) and NOT with early onset preeclampsia ( $($ LOP $\geq 34$ weeks gestation, EOP $<34$ weeks gestation) [14] (Figure 1). Early onset (EOP) is the major complication of human pregnancy with terrible maternal/fetal morbidities/mortality. Hopefully LOP is much less severe with particularly a high probability of $100 \%$ survival of new-borns. Hopefully again, LOP represents $90 \%$ of preeclampsia cases in developed countries and $70 \%$ of cases in other parts of the world [15]. Then, we thought to test if we could counterbalance the morbid effect of overweight/obesity and possibly lower the rate of LOP in a population.

We have then recently retrospectively tested the effect of achieving optGWG $( \pm 2 \mathrm{~kg})$ in our reunionnese population by a mathematical simulation on an 18 -year (2001-2018) [16] and 19-year historical cohort. (2001-2019) [17] on 57,000, and then 59,000 term pregnancies.

1) The result concerning late onset preeclampsia is that we should almost halve the incidence of this disease in overweight and, moreover in all kind of obese women (class I to III), by achieving an optGWG [16]. 


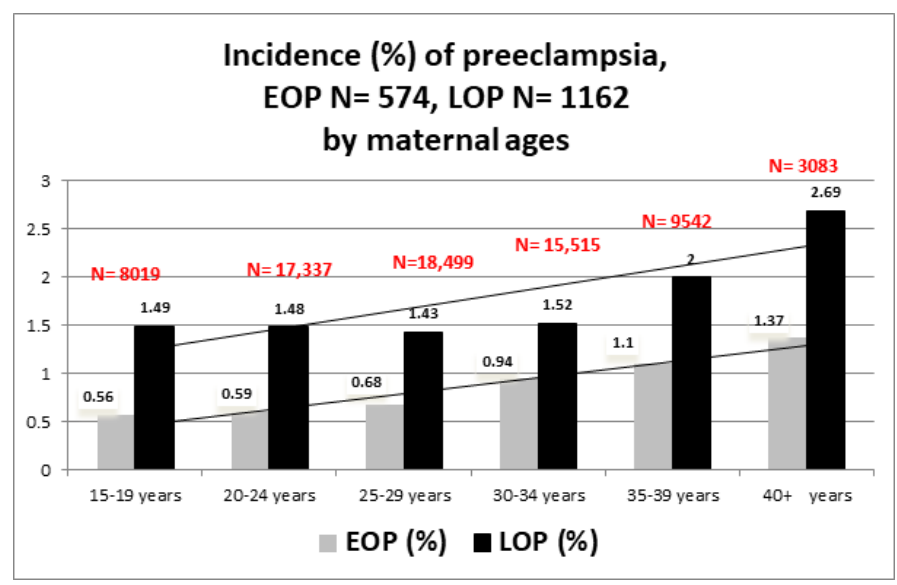

Incidence (\%) of preeclampsia,

EOP $N=574$, LOP $N=1162$

by maternal pre-pregnancy $B M I$

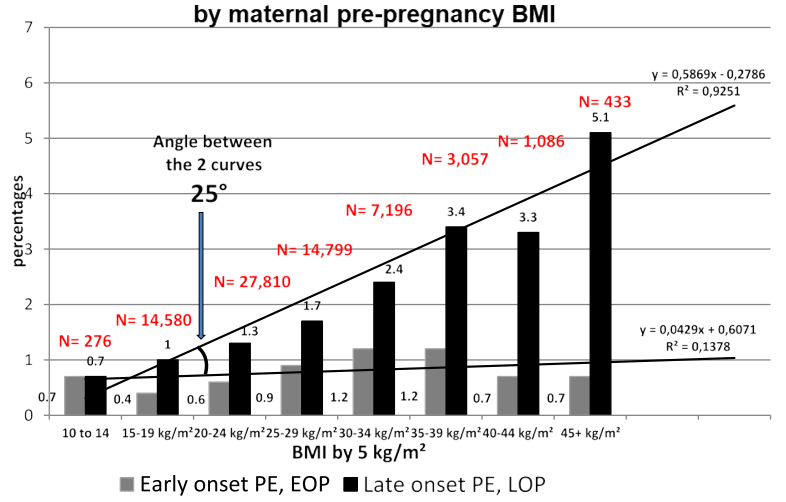

Figure 1. Different behaviours between maternal ages and maternal pre-pregnancy BMI concerning early onset and late onset preeclampsia [14].

Considering other maternal-foetal important morbidities [17].

2) The rate of caesarean sections would be diminished by some $30 \%$ in overweight-obese women

3) The rate of large for gestational age (LGA babies) would be of $10 \%$ (the very definition of the linear equation) instead of some $25 \%$ in severely obese women.

4) The rate of macrosomic babies ( $\geq 4 \mathrm{~kg}$ ) would be diminished by 30 to $40 \%$ following the different gradations of severe obesities (class II and III).

5) Transfers in neonatal departments of new-borns is significantly lower for class II and III women

6) The rate of small for gestational age (SGA babies) would be of $10 \%$ (again, the very definition of the linear equation) instead of some $25 \%$ in lean women.

7) Concerning gestational diabetes mellitus (GDM), as it is a retrospective study, we could not yet show an effect: as the diagnosis of GDM is made during pregnancy around 20-24 weeks gestation the "evil" is already done at this period in case of excessive weight gain in overweight/obese women. We propose that a prospective followup and counselling, since the first prenatal visit (the linear equation is based on PRE-pregnancy BMI) would allow women to reach the 20th24th week with an adequate GWG. Therefore, and mechanically, the rate of GDM would become lower in obese population.
In summary, we may have significant health (and cost) benefits by lowering c-section rates, term preeclampsia, macrosomic babies and LGA babies in overweight/obese women and low-birthweights babies in lean women.

\section{Interesting possible difference between "maternal- age-5” AND "pre-pregnancy-BMI-5" [14]}

As shown as example in figure 1, "maternal-age5" and "Pre pregnancy BMI5" with the example of preeclampsia: the well-known higher preeclampsia risk with maternal ages is equally shared for early onset EOP ( $<34$ weeks) and for late-onset LOP: the two curves are PARALLEL. For maternal pre-pregnancy BMI, the curves make a $25^{\circ}$ angle. In other occasions (not shown on a figure 1), "maternal-age5" and "Pre pregnancy BMI5" are both parallel with the example of caesarean section risk [1,7].

\section{Conclusion}

In general science, it is accepted in physics for example that nature laws can be translated in mathematical models/equations. But physicists argue also that biologists are far back behind "biologist have not yet found mathematical laws to describe their science" [18]. We propose as a beginning that, in human reproduction, concerning a) maternal ages categories by 5 years of age (15-19, 20-24 etc..) and b) maternal physiological BMI (before any pregnancy), also, interestingly, by categories of $5 \mathrm{~kg} / \mathrm{m}^{2}\left(15-19,20-24 \mathrm{~kg} / \mathrm{m}^{2}\right.$ etc.) we have linear equations of paramount consequences. These linear equations suggest that there are some biological underlying principles, which may be interpreted as mathematical biological laws. Even not fully understood, these findings imply immediate useful and practical consequences. In the particular case of BMI as a cornerstone of safer human deliveries is the triumph of Quételet's premonition 2 centuries ago [19].

\section{References}

1. Barau G, Robillard PY, Hulsey TC, Dedecker F, Laffite A, et al. (2016) Linear association between maternal pre-pregnancy body mass index and risk of caesarean section in term deliveries. BJOG 113: 1173-1177.

2. Robillard PY. Rapport 2001-2017 du Relevé épidémiologique périnatal SudRéunion. Available from: https://www.repere.re/fileadmin/user_upload/Pro/ RAPPORT_2001-2017_Sud-Reunion.pdf

3. Dedekker F, de Baillencourt T, Barau G, Fortier D, Robillard PY, et al. (2005) Etude des facteurs de risques obstéricaux dans le suivi de 365 grossesses primipares adolescentes à l'île de la Réunion. J Gynecol Obstet Biol Reprod 34: 694-701.

4. Iacobelli S, Robillard PY, Gouyon JB, Hulsey TC, Barau G, et al. (2012) Obsteric and neonatal outcomes of adolescent primiparous singleton pregnancies: a cohort study in the south of Reunion island, Indian Ocean. J Matern Fetal Neonatal Med 25: 25912596. [Crossref]

5. Iacobelli S, Robillard PY, Gouyon JB, Nichols M, Boukerrou M, et al. (2014) Longitudinal health outcome and wellbeing of mother-infant pairs after adolescent pregnancy in Reunion Island, Indian Ocean. Int J Gynaecol Obstet 125: 44-48.

6. Fraser AM, Brockert JE, Ward RH (1995) Association of young maternal age with adverse reproductive outcomes. $N$ Engl J Med 332: 1113-1117. [Crossref]

7. Robillard PY, Hulsey TC, Boukerrou M, Bonsante F, Dekker G, et al. (2018) Linear association between maternal age and need of medical interventions at delivery in primiparae: a cohort of 21,235 singleton births. J Matern-Fetal Neonatal Med 31: 2027-2035. [Crossref]

8. Robillard PY, Boukerrou M, Bonsante F, Hulsey TC, Dekker G, et al. (2017) Linear association between maternal age and spontaneous breech presentation in singleton pregnancies after 32 weeks gestation. J Matern Fetal Neonatal Med 9: 1-6.

9. Robillard PY, Hulsey TC, Boukerrou M, Bonsante F, Dekker G, et al. (2019) Active medical interventions at birth in primiparae have a linear association with maternal ages $(\mathrm{Y}=1.4 \mathrm{X})$. Ann Obstet Gynecol 2: 1009. 
Pierre-Yves R (2020) Strange linearities in human pregnancy. The immediate immense consequences for personal women's reproductive lives

10. IOM (2009) Weight gain during pregnancy : reexamining the Guidelines. Institute of Medicine (US), National Research Council (US), Committee to Reexamine IOM Pregnancy Weight Guidelines.

11. WHO (2000) Obesity: Preventing and Managing the Global Epidemic Report of a WHO Consultation; 2000. 0512-3054 (Print) 0512-3054 (Linking).

12. Robillard PY, Dekker G, Boukerrou M, Le Moullec N, Hulsey TC (2018) Relationship between pre-pregnancy maternal BMI and optimal weight gain in singleton pregnancies. Heliyon 4: e00615.

13. Gestational weight gain calculator (English version) on smart phone. REPERE.RE (Reseau Perinatal REunion). Avaliable from: https://www.repere.re/infos-parents/lesuivi-de-ma-grossesse/weight-gain-during-my-pregnancy.html?L=968\%27\%5B0\%5D

14. Robillard PY, Dekker G, Scioscia M, Bonsante F, Iacobelli S, et al. (2019) Increased BMI has a linear association with late-onset preeclampsia: A population-based study. PLoS One 14: e0223888. [Crossref]
15. Robillard PY, Dekker G, Chaouat G, Elliot MG, Scioscia M (2019) High incidence of early onset preeclampsia is probably the rule and not the exception worldwide. 20th anniversary of the reunion workshop. A summary. J Reprod Immunol 133: 30-36. [Crossref]

16. Robillard PY, Dekker GA, Boukerrou M, Boumahni B, Hulsey TC, et al. (2020) Gestational weight gain and rate of late-onset preeclampsia: a retrospective analysis on 57,000 pregnancy in Reunion island. BMJ Open 10: e36549. [Crossref]

17. Robillard PY, Dekker GA, Boukerrou M, Boumahni B, Hulsey TC, et al. (2020) The urgent need to optimize gestational weight gain in overweight/obese women to lower maternal-fetal moribidities: a retrospective analysis on 59,000 singleton term pregnancies. ARCH Women Health Care 3: 1-9.

18. Klein E. Several conferences on physics, quantic mechanic, general relativity etc. YouTube.

19. Robillard PY. (2020) Adolphe Quetelet's premonition two centuries after: besides its implications in physiology (obesity, Type 2 Diabetes), its paramount importance in human pregnancy. J Diabet Metabol Complica 2: 1-3.

Copyright: $@ 2020$ Pierre-Yves R. This is an open-access article distributed under the terms of the Creative Commons Attribution License, which permits unrestricted use, distribution, and reproduction in any medium, provided the original author and source are credited. 